Supporting information

\title{
Ultrasensitive Nanostructured Platform for the Electrochemical Sensing of Hydrazine
}

\author{
Bikash Kumar Jena and C. Retna Raj \\ Department of Chemistry \\ Indian Institute of Technology \\ Kharagpur 721 302, India \\ E-mail: crraj@chem.iitkgp.ernet.in
}




\section{Figure 1s}

UV-visible diffuse reflection spectra of nanoparticles on MPTS sol-gel network modified gold-coated glass slide. (a) MPTS modified glass slide, (b) GNS and (c) GNE.

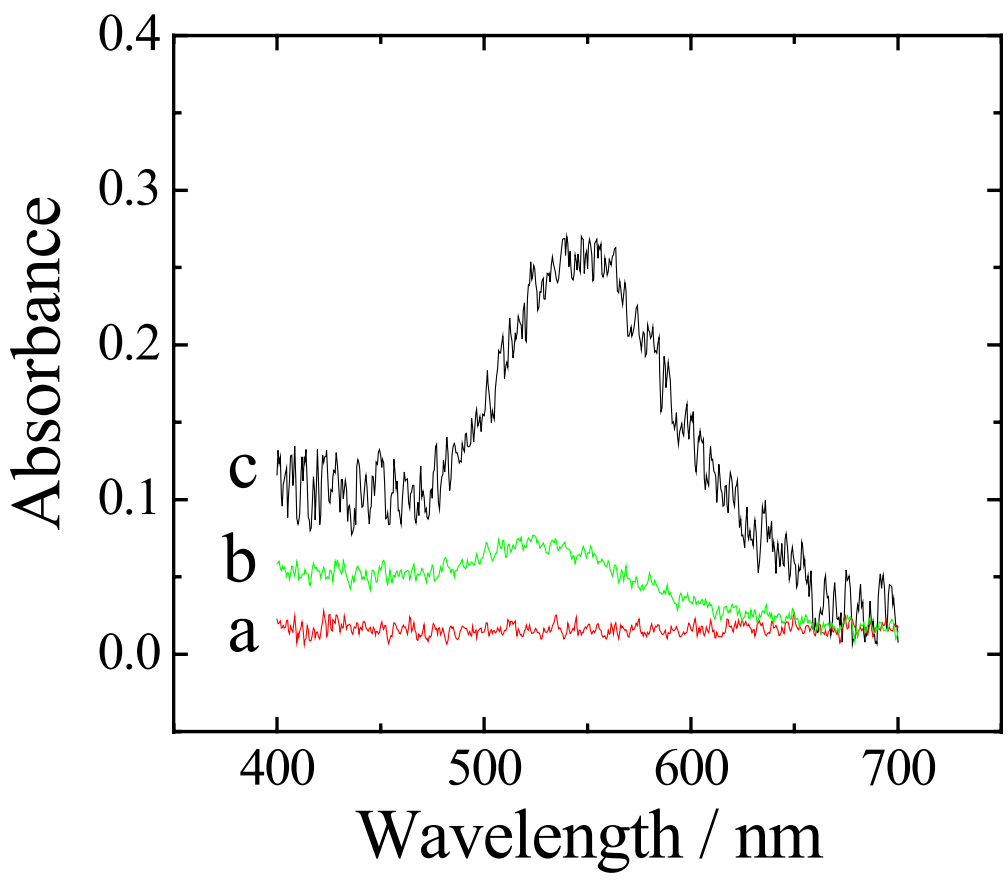




\section{Figure 2s}

XRD pattern obtained for (a) MPTS modified coverslip and (b) GNEs on MPTS modified coverslip.

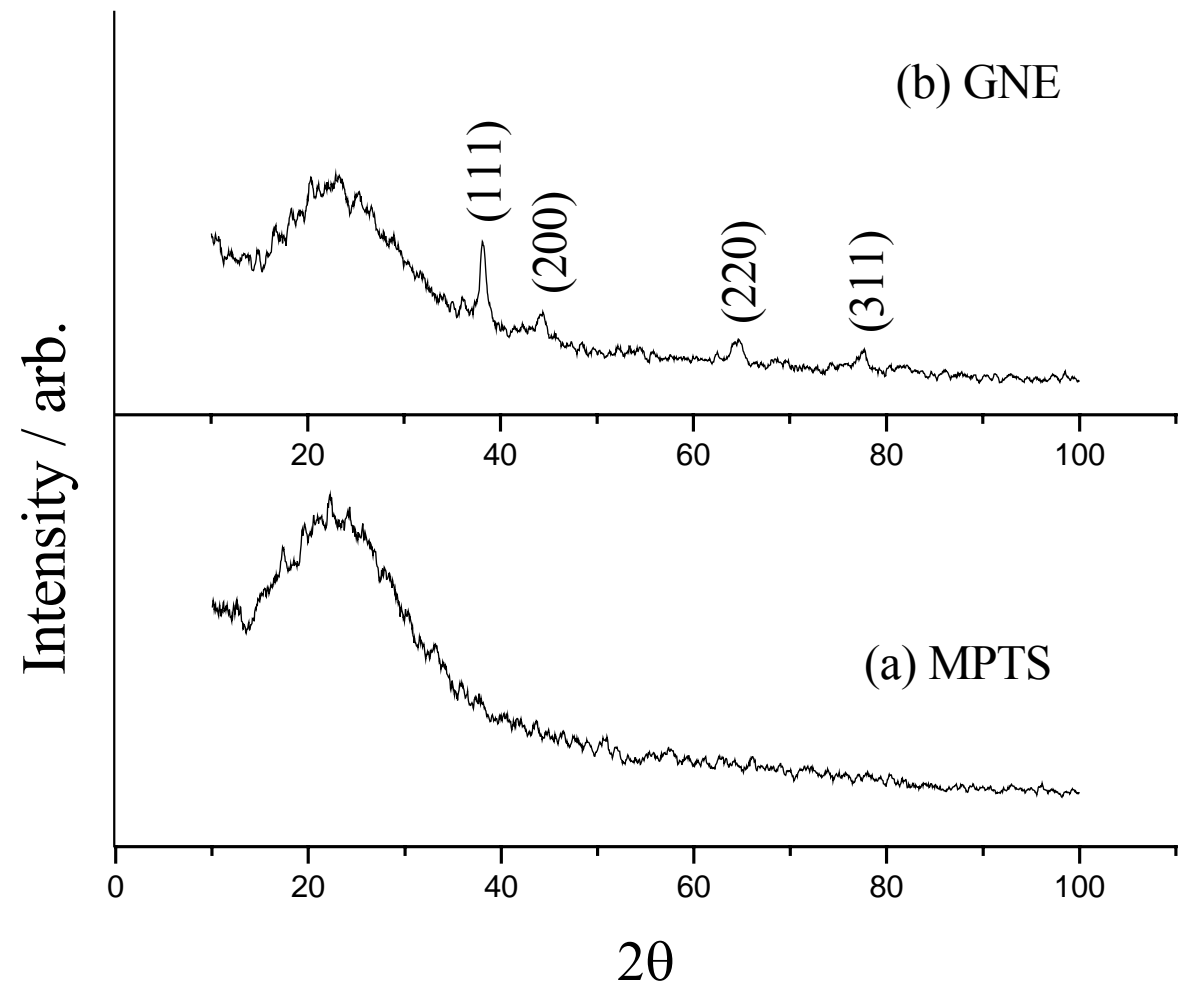


Figure 3s

Cyclic voltammogram obtained for (a) GNS and (b) GNE electrodes in 0.1 M KOH.

Sweep rate $10 \mathrm{mV} / \mathrm{s}$.

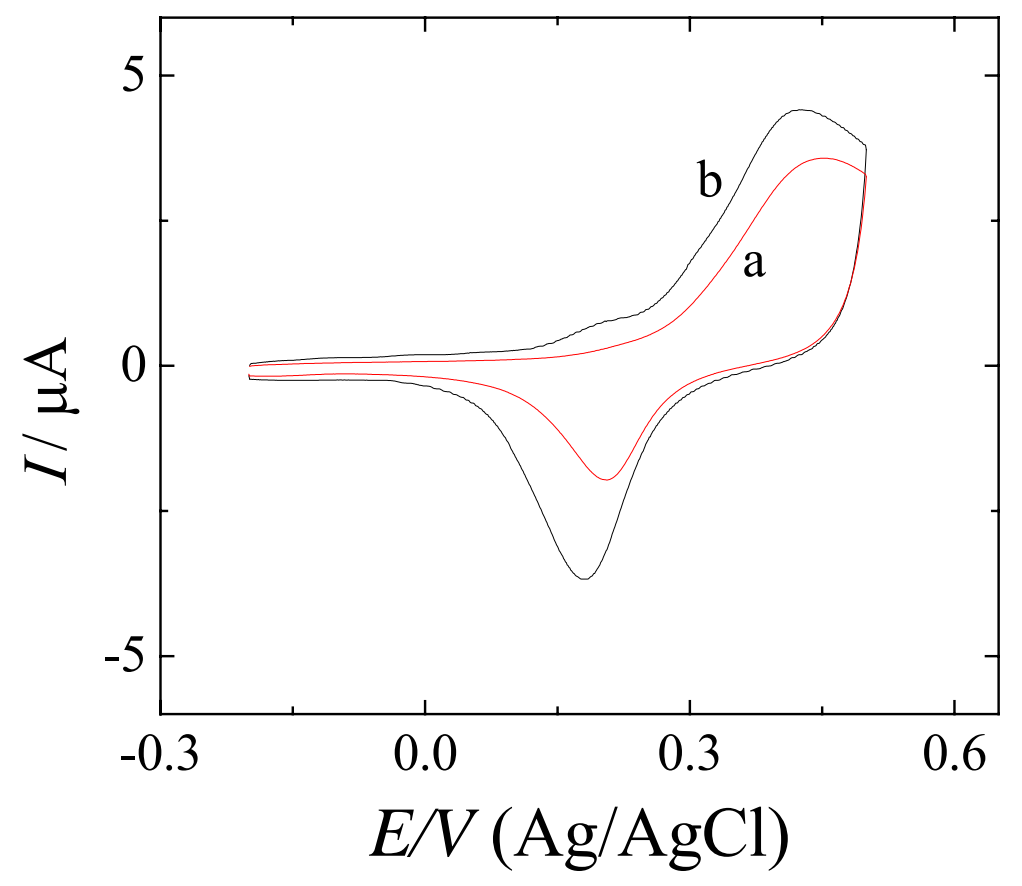




\section{Figure 4s}

Cyclic voltammograms for the oxidation of hydrazine $(0.2 \mathrm{mM})$ at GNE electrode at different pHs: (a) 9.2, (b) 8.5, (c) 8, (d) 7.5, (e) 7, (f) 6.5, (g) 6, (h) 5.5, (i) 5, (j) 4.5, (k) 4, and (1) 3 .

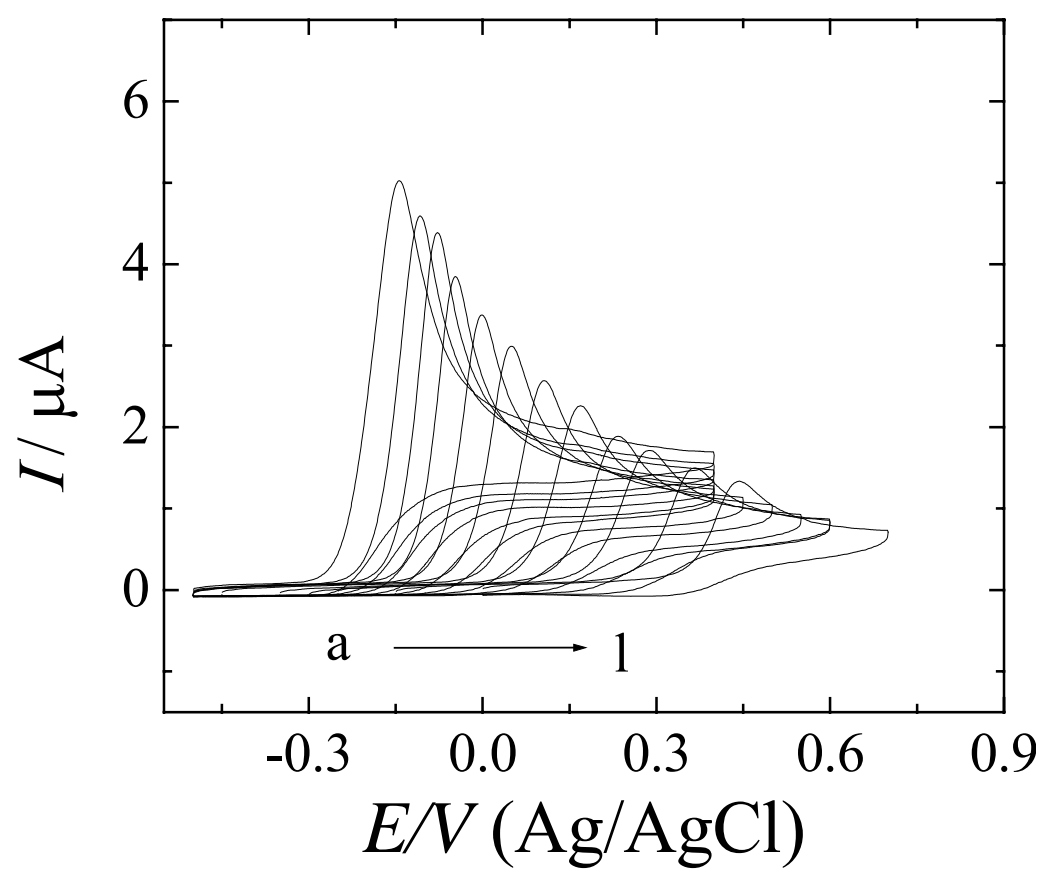




\section{Figure 5s}

Operational stability of GNE electrode under continuous polarization at the potential of $-0.1 \mathrm{~V}$ in a stirred supporting electrolyte solution containing $30 \mathrm{nM}$ hydrazine. The noise is due to stirring of the supporting electrolyte.

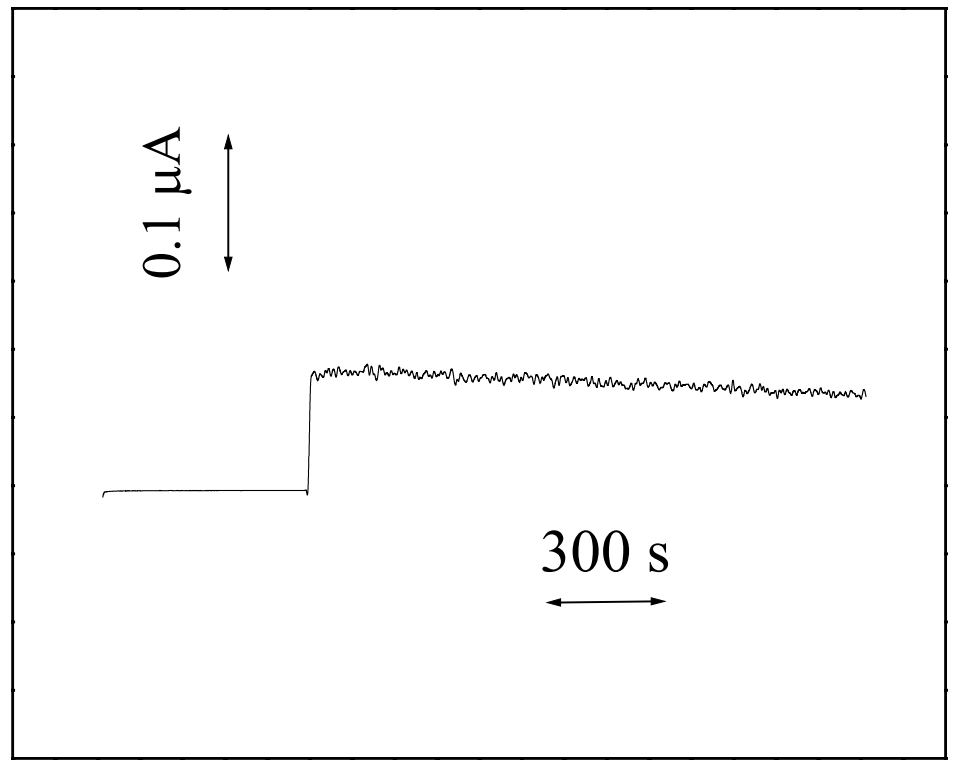




\section{Figure 6s}

Plot demonstrating the long-term storage stability of the GNE electrode. The electrode was used for the sensing of hydrazine in $0.1 \mathrm{M}$ PBS on every day and kept in PBS in the interim.

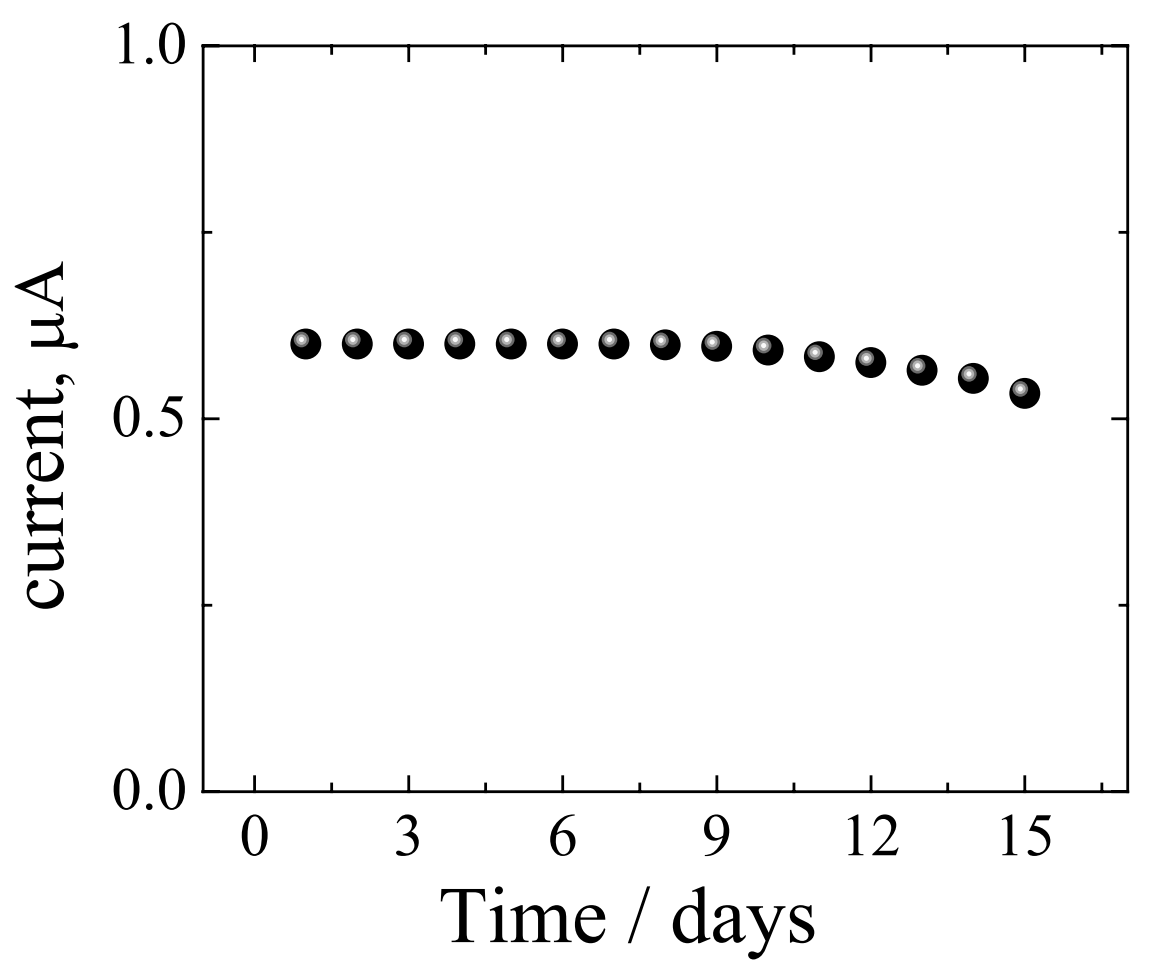

